\title{
Ultrasonic sound speed analysis of hydrating calcium sulphate hemihydrate
}

\author{
A. C. J. de Korte $\cdot$ H. J. H. Brouwers
}

Received: 29 October 2010/ Accepted: 1 June 2011/Published online: 28 June 2011

(C) The Author(s) 2011. This article is published with open access at Springerlink.com

\begin{abstract}
This article focuses on the hydration, and associated microstructure development, of $\beta$-hemihydrate to dihydrate (gypsum). The sound velocity is used to quantify the composition of the fresh slurry as well as the hardening and hardened-porous-material. Furthermore, an overview of available hydration kinetic and volumetric models for gypsum is addressed. The presented models predict the sound velocity through slurries and hardened products. These states correspond to the starting and ending times of the hydration process. The present research shows that a linear relation between the amount of hydrationproduct (gypsum) formed and sound velocity (Smith et al., J Eur Ceram Soc 22(12):1947, 2002) can be used to describe this process. To this end, the amount of hydrationproduct formed is determined using the equations of Schiller (J Appl Chem Biotechnol 24(7):379, 1974) for the hydration process and of Brouwers (A hydration model of Portland cement using the work of Powers and Brownyard, 2011) for the volume fractions of binder, water and hydration products during the hydration process.
\end{abstract}

$\begin{array}{ll}\text { Abbreviations } \\ \text { C } & \text { Volume fraction in water } \\ c & \text { Sound velocity } \\ \text { wbr } & \text { Water/binder ratio }(\mathrm{m} / \mathrm{m})\end{array}$

A. C. J. de Korte $(\square)$

Department of Civil Engineering, Faculty of Engineering

Technology, University of Twente, P.O. Box 217,

7500 AE Enschede, The Netherlands

e-mail: a.c.j.dekorte@ctw.utwente.nl

H. J. H. Brouwers

Department of Architecture, Building and Planning, Eindhoven University of Technology, P.O. Box 513, 5600 MB Eindhoven,

The Netherlands

\author{
Subscript \\ air Air \\ DH Di-hydrate (gypsum) \\ f Fluid \\ HH Hemihydrate \\ hp Hardened product \\ s Solid \\ sl Slurry \\ t Total \\ w Water \\ Greek \\ $\alpha$ Hydration degree \\ $\rho \quad$ Specific density \\ $\phi$ Volume fraction
}

\section{Introduction}

Currently, the hydration of hemihydrate to dihydrate and cement is studied by IR, SEM and Vicat techniques. Because the speed of hydration it is more difficult to measure the hydration curve and the different processes which take place. For the measurement of the hydration of cement and concrete, in the last decade, ultrasonic sound velocity measurements have been applied successfully [1-3]. This method has the advantage over the more traditional methods, such as the aforementioned Vicat-needle, SEM and IR, that ultrasonic measurements are continuous [4], and that they provide information about the microstructure development and the related properties like strength development [1]. Especially for hemihydrate hydration, due to the short hydration time, it is difficult to stop the hydration for discontinuous measurements. The ultrasonic sound velocity method used here is developed and patented by the University of Stuttgart [5]. 
The combining of ultrasonic measurements and volumetric composition has not been studied for hemihydrates yet, so far only studies are reported concerning cement paste and mortar, and also here these models were never combined to an overall volumetric composition model. Hence, this article will focus on the application of the ultrasonic sound velocity measurement for assessing the hydration curve of hemihydrate to gypsum. Therefore, it will be combined with information about the volume fractions of binders and hardened material during hydration and the classic hydration-time relations given by Schiller [6]. The currently used models do not fully combine this information, because either only focus on the microstructure development [7] or the effect of additives on the hydration [1, 2, 8]. In this article, a relation is established between ultrasonic speed and microstructure during hydration, from fresh state after mixing until hardened state at fully completed hydration.

\section{Sound velocity of materials}

This section describes the sound velocity through materials. Therefore, first a short introduction is given about sound velocity through fluid and non-porous material ('Introduction' section). Afterwards, the velocity through slurries ('Sound velocity of a slurry' section) and porous material ('Sound velocity of porous solid' section) is given. These two sections describe the starting and final states during the hydration, respectively.

\section{Introduction}

There are two methods to obtain the sound speed of the materials. The first method is the use of values from literature. Table 1 shows the sound speed through some materials. Besides this direct method, there is a second method to acquire the value of sound speed. This indirect method is based on the elastic modulus and density of the material and reads

$c=\sqrt{\frac{K}{\rho}}$, with $c$ the sound speed, $K$ the bulk modulus and $\rho$ the specific density. This method is suitable for fluids and gases, but it is not valid for solid materials. Since solid materials can support both longitudinal and shear waves, the shear modulus besides the bulk modulus influences the sound velocity. Therefore, the equation for solids read

$c_{\text {long }}=\sqrt{\frac{K+\frac{4}{3} G}{\rho}}$,

where $K$ and $G$ are the bulk and shear modulus of the solid, respectively, and $\rho$ its specific density. Table 1 shows the elastic, bulk and shear modulus of several materials, as well as that of the fluids water and air. When applying Eqs. 1 and 2 , the results for (non-porous) gypsum are 4289-4448 and $5019-5210 \mathrm{~m} / \mathrm{s}$, respectively. The results of both equations are lower than the experimental value of $6800 \mathrm{~m} / \mathrm{s}$ provided by Losso and Viveiros [9]. This value is too high according to Y. Sakalli [Personal Communication, 2011].

Equations 1 and 2 tend to underestimate the sound velocity through solids. This is even more true for porous solids, which also contain voids. In 'Paste model for hydrating hemihydrate' section, the composition of a hemihydrates-water-gypsum system is addressed, used here for the development of a new model relating sound velocity and compositional properties.

\section{Sound velocity of a slurry}

This sub-section describes the sound velocity of a slurry, i.e. a suspension, containing entrapped air. Robeyst et al. [1] presented a model for ultrasonic velocity through fresh cement mixtures, based on the theoretical model of Harker and Temple [10] for ultrasonic propagation in colloids. According to these models, the effective wave velocity $\left(c_{\mathrm{e}}\right)$ in a suspension is given by:

$$
\begin{aligned}
c_{\mathrm{e}}^{2}= & {\left[\left(\phi_{\mathrm{t}} \frac{1}{K_{\mathrm{f}}}+\left(1-\phi_{\mathrm{t}}\right) \frac{1}{K_{\mathrm{s}}}\right)\right.} \\
& \left.\times\left(\frac{\rho_{\mathrm{f}}\left(\rho_{\mathrm{s}}\left(\phi_{\mathrm{t}}+\left(1-\phi_{\mathrm{t}}\right) S\right)+\rho_{\mathrm{f}} S \phi_{\mathrm{t}}\right)}{\rho_{\mathrm{s}} \phi_{\mathrm{t}}^{2}+\rho_{\mathrm{f}}\left(S+\phi_{\mathrm{t}}\left(1-\phi_{\mathrm{t}}\right)\right)}\right)\right]^{-1}
\end{aligned}
$$

Table 1 Relevant physical properties of different materials; sound velocity of water, air, and steel according to [36]; sound velocity of gypsum according to [9]; elastic, bulk, and shear modulus and Poisson ratio according to [37-39]; bulk modulus air and water [39]

\begin{tabular}{llllll}
\hline & $\begin{array}{l}\text { Specific density } \\
\left(\mathrm{kg} / \mathrm{m}^{3}\right)\end{array}$ & $\begin{array}{l}\text { Sound speed } \\
(\mathrm{m} / \mathrm{s})\end{array}$ & $\begin{array}{l}\text { Elastic modulus } \\
(\mathrm{GPa})\end{array}$ & $\begin{array}{l}\text { Bulk modulus } \\
(\mathrm{GPa})\end{array}$ & $\begin{array}{l}\text { Shear modulus } \\
(\mathrm{GPa})\end{array}$ \\
\hline Water & 1000 & 1497 & & $\begin{array}{l}\text { Poisson } \\
\text { ratio }\end{array}$ \\
Air & & 346 & & 0.142 & \\
Steel & 7700 & 5930 & 170 & 79.3 & $15.7-17$ \\
Dihydrate & 2310 & 6800 & 45.7 & $42.5-45.7$ & 24.2 \\
Hemihydrate & 2619 & & 62.9 & 52.4 & 0.33 \\
Anhydrite & 2520 & & 50 & 54.9 & 0.30 \\
\hline
\end{tabular}


with the subscript ' $\mathrm{f}$ ' referring to the fluid, 's' to the solid, and $\phi_{\mathrm{t}}$ to the fluid volume fractions. The parameter $S$ generally depends on the size and shape of the particles, the void fraction and the continuous phase viscosity [11], but it can be approximated by Eq. 4 for spherical particles in a fluid [12]

$S=\frac{1}{2}\left(\frac{1+2\left(1-\phi_{\mathrm{t}}\right)}{\phi_{\mathrm{t}}}\right)$.

When also entrapped air is present in the fluid, the compressibility of the continuous phase can be corrected, assuming the air to be uniformly distributed

$\frac{1}{K_{\mathrm{f}}}=\left(1-\frac{c_{\mathrm{air}}}{\phi_{\mathrm{t}}}\right) \frac{1}{K_{\mathrm{water}}}+\frac{c_{\mathrm{air}}}{\phi_{\mathrm{t}}} \frac{1}{K_{\mathrm{air}}}$,

with $c_{\text {air }}$ as the air volume fraction in the voids of the fluid and $K_{\text {air }}$ the bulk modulus of air.

Sound velocity of porous solids

The equations from 'Introduction' section are not directly applicable to porous materials. Therefore, this subsection will describe two ways to calculate the sound velocity through porous material. 'Indirect method' section describes the indirect methods, in which the sound velocity is based on the bulk and shear modulus like in Eqs. 1 and 2. 'Direct method' section will focus on the direct methods, in which the calculations are based on the theoretical sound velocities of the non-porous materials as presented in Table 1.

\section{Indirect method}

When using the indirect method for calculation, the sound velocity through porous materials, the bulk modulus, shear modulus and density need to be computed. Analogue to thermal conductivity one could expect the boundaries for a material to be given by the parallel and series arrangement. Hoyos et al. [13] uses the parallel arrangement, this equation reads

$K_{\mathrm{e}}^{-1}=\left(1-\phi_{\mathrm{t}}\right) K_{\mathrm{s}}^{-1}+\phi_{\mathrm{t}} K_{\mathrm{f}}^{-1}$,

with $K_{\mathrm{e}}$ the effective bulk modulus, $K_{\mathrm{s}}$ the bulk modulus of solid and $K_{\mathrm{f}}$ the bulk modulus of the fluid. The series equation reads

$K_{\mathrm{e}}=\left(1-\phi_{\mathrm{t}}\right) K_{\mathrm{s}}+\phi_{\mathrm{t}} K_{\mathrm{f}}$.

The series arrangement can be used for the bulk and shear modulus. But using the parallel arrangement, the shear modulus $\left(G_{\mathrm{e}}\right)$ cannot be calculated since fluids do not have a shear modulus. In order to calculate the shear modulus, the relation between the bulk modulus and shear modulus [14] is as follows:
$G_{\mathrm{e}}=\frac{3 K(1-2 v)}{2(1+v)}$

with $v$ the Poisson ratio of the solid. Arnold et al. [15] give the following equation for very porous media $\left(\phi_{t}>0.4\right)$ with spherical pores

$K_{\mathrm{e}}=K_{\mathrm{s}} \frac{2(1-2 v)\left(1-\phi_{\mathrm{t}}\right)}{3(1-v)}$

with $K_{\mathrm{s}}$ as the bulk modulus at zero void fraction and $v$ the poisson ratio at zero void fraction.

Besides a difference in bulk and shear modulus of a porous material, also the density will be different. The equation for effective density reads

$\rho_{\mathrm{e}}=\left(1-\phi_{\mathrm{t}}\right) \rho_{\mathrm{s}}+\phi_{\mathrm{t}} p_{\mathrm{f}}$

with $\rho_{\mathrm{s}}$ and $\rho_{\mathrm{f}}$ as the density of the solid and the fluid, respectively.

Equations 6-10 can be used in Eqs. 1 and 2 to calculate the sound velocity of a porous material.

Summarizing, the combined equations for parallel arrangement without taking in account the contribution of the shear modulus read

$c_{\mathrm{e}}=\sqrt{\frac{K_{\mathrm{s}} K_{\mathrm{f}}}{\left(1-\phi_{\mathrm{t}}\right) K_{\mathrm{f}}+\phi_{\mathrm{t}} K_{\mathrm{s}}} \cdot \frac{1}{(1-\phi) \rho_{\mathrm{s}}+\phi_{\mathrm{t}} \rho_{\mathrm{f}}}}$

by combination of Eqs. 1, 6 and 10, for the series arrangement without shear modulus contribution, the sound velocity reads

$c_{\mathrm{e}}=\sqrt{\frac{K_{\mathrm{s}}+\phi_{\mathrm{t}}\left(K_{\mathrm{f}}-K_{\mathrm{s}}\right)}{\rho_{\mathrm{s}}+\phi_{\mathrm{t}}\left(\rho_{\mathrm{f}}-\rho_{\mathrm{s}}\right)}}$

by combination of Eqs. 1, 7 and 10, for the bulk modulus according to Arnold et al. [15] the sound velocity reads

$c_{\mathrm{e}}=\sqrt{K_{\mathrm{s}} \frac{(2-v)\left(1-\phi_{\mathrm{t}}\right)}{3(1-v)} \cdot \frac{1}{\left(1-\phi_{\mathrm{t}}\right) \rho_{\mathrm{s}}+\phi_{\mathrm{t}} \rho_{\mathrm{f}}}}$

by combination of Eqs. 1, 9 and 10, for the parallel arrangement with shear modulus according to Landau [14] the sound velocity reads

$c_{\mathrm{e}}=\sqrt{\frac{K_{\mathrm{s}} K_{\mathrm{f}}}{\left(1-\phi_{\mathrm{t}}\right) K_{\mathrm{f}}+\phi K_{\mathrm{s}}} \cdot \frac{1}{\left(1-\phi_{\mathrm{t}}\right) \rho_{\mathrm{s}}+\phi_{\mathrm{t}} \rho_{\mathrm{f}}} \cdot\left(1+\frac{2(1-2 v)}{(1+v)}\right)}$

by combination of Eqs. 2, 6, 8 and 10, for the series arrangement with shear modulus according to Landau [14], the sound velocity reads

$c_{\mathrm{e}}=\sqrt{\frac{K_{\mathrm{s}}+\phi_{\mathrm{t}}\left(K_{\mathrm{f}}-K_{\mathrm{s}}\right)}{\rho_{\mathrm{s}}+\phi_{\mathrm{t}}\left(\rho_{\mathrm{f}}-\rho_{\mathrm{s}}\right)} \cdot\left(1+\frac{2(1-2 v)}{(1+v)}\right)}$ 
by combination of Eqs. 2, 7, 8 and 10, and for the bulk modulus according to Arnold et al. [15] with shear modulus according to Landau [14], the sound velocity reads

$c_{\mathrm{e}}=\sqrt{K_{\mathrm{s}} \frac{(2-v)\left(1-\phi_{t}\right)}{3(1-v)} \cdot \frac{1}{\left(1-\phi_{\mathrm{t}}\right) \rho_{\mathrm{s}}+\phi_{\mathrm{t}} \rho_{\mathrm{f}}} \cdot\left(1+\frac{2(1-2 v)}{(1+v)}\right)}$

by combination of Eqs. 2, 8, 9 and 10 with $c_{\mathrm{e}}$ as the effective sound speed, $K_{\mathrm{s}}$ and $K_{\mathrm{f}}$ the bulk modulus of the solid and the fluid, respectively, $v$ the poison ratio, $\rho_{\mathrm{s}}$ and $\rho_{\mathrm{f}}$ the specific density of the solid and the fluid, respectively, and $\phi_{\mathrm{t}}$ the void fraction of the mixture. Equations 11-16 are applied and validated in 'Applying the volumetric models to sound velocity measurements' section.

\section{Direct method}

The sound velocity of a porous material can also calculated directly from the individual sound velocities of the individual phases. Roth et al. [16] used a simple equation to predict the effective sound speed in a porous medium. This equation reads

$c_{\mathrm{e}}=c_{\mathrm{s}}\left(1-\phi_{\mathrm{t}}\right)$

with $c_{\mathrm{s}}$ the sound speed in the non-porous material and $\phi_{\mathrm{t}}$ the void fraction. Dalui et al. [17] have added an exponent

$c_{\mathrm{e}}=c_{\mathrm{s}}\left(1-\phi_{\mathrm{t}}\right)^{\mathrm{n}}$

with exponent $n$ being an empirical constant. For $\alpha$-hemihydrate, Dalui et al. [17] proposed $n=0.84$ and $c_{\mathrm{s}}=4571 \mathrm{~m} / \mathrm{s}$.

A drawback of these empirical equations is that in the limit of the void fraction approaching unity, a sound velocity of zero is obtained, which is obviously not correct. Therefore, here an additional term is added to Eqs. 17 and 18 which takes into account the sound velocity of the fluid:

$c_{\mathrm{e}}=c_{\mathrm{s}}\left(1-\phi_{\mathrm{t}}\right)+c_{\mathrm{f}} \phi_{\mathrm{t}}$

and

$c_{\mathrm{e}}=c_{\mathrm{s}}\left(1-\phi_{\mathrm{t}}\right)^{n}+c_{\mathrm{f}} \phi_{\mathrm{t}}^{n}$

with $c_{\mathrm{f}}$ being the sound speed of the fluid. Equations 17-20 are based on a parallel arrangement. Another possibility is to use a series arrangement [18], and the equation for this arrangement reads

$c_{\mathrm{e}}=\frac{c_{\mathrm{s}} c_{\mathrm{f}}}{\left(1-\phi_{\mathrm{t}}\right) c_{\mathrm{f}}+\phi_{\mathrm{t}} c_{\mathrm{s}}}$

with $c_{\mathrm{e}}$ as the effective velocity, $c_{\mathrm{s}}$ the velocity of the solid phase, $c_{\mathrm{f}}$ the velocity of the fluid and $\phi_{\mathrm{t}}$ the void fraction.

\section{Paste model for hydrating hemihydrate}

In this section, a paste model for hydration of calcium sulphates is presented. This paste model is subsequently used for the calculation of the volume fractions of solids and voids in the slurry and solid materials. These volume fractions are needed for the calculation of the sound speed through porous media in following sections, since the void fraction influences the bulk and shear modulus as well as the density of the material, and hence the sound speed.

The model of Brouwers [19] is used to describe the volume fractions of binder, hardened product, water and shrinkage before, during and after hydration. This model makes use of the molar mass of the reactant and product as well as the reaction stoichiometry. It can be used for both $\alpha$ - and $\beta$-hemihydrate as well as anhydrite. The volume fractions read

$\phi_{\mathrm{hp}}=\frac{\alpha\left[\frac{v_{\mathrm{c}}}{v_{\mathrm{w}}}+\frac{w_{\mathrm{n}} v_{\mathrm{n}}}{v_{\mathrm{w}} c}\right]}{\frac{v_{\mathrm{c}}}{v_{\mathrm{w}}}+\frac{w_{0}}{c_{0}}}$

$\phi_{\mathrm{c}}=\frac{(1-\alpha)\left[\frac{v_{\mathrm{c}}}{v_{\mathrm{w}}}\right]}{\frac{v_{\mathrm{c}}}{v_{\mathrm{w}}}+\frac{w_{0}}{c_{0}}}$

$\phi_{\mathrm{w}}=\frac{\frac{w_{0}}{c_{0}}-\alpha\left[\frac{w_{\mathrm{n}}}{c}\right]}{\frac{v_{\mathrm{c}}}{v_{\mathrm{w}}}+\frac{w_{0}}{c_{0}}}$

$\phi_{\mathrm{s}}=\frac{\alpha\left[1-\frac{v_{\mathrm{n}}}{v_{\mathrm{w}}}\right] \frac{w_{\mathrm{n}}}{c}}{\frac{v_{\mathrm{c}}}{v_{\mathrm{w}}}+\frac{w_{0}}{c_{0}}}$

with $\phi_{\mathrm{c}}, \phi_{\mathrm{hp}}, \phi_{\mathrm{w}}$ and $\phi_{\mathrm{s}}$ as the volume fractions of binder, hardened product, water and shrinkage, respectively, and $\alpha$ the hydration degree, $w_{\mathrm{n}} / c$ the mass of non-evaporable water on mass of reacted hemihydrates, $v_{\mathrm{c}} / v_{\mathrm{w}}$ the specific volume ratio of hemihydrate on water, $w_{\mathrm{n}} / c_{0}$ the initial water/binder ratio and $v_{\mathrm{n}} / v_{\mathrm{w}}$ the volume ratio of non-evaporable water on water. The values for $w_{\mathrm{n}} / c, v_{\mathrm{c}} / v_{\mathrm{w}}$ and $v_{\mathrm{n}} / v_{\mathrm{w}}$ can be found in Brouwers [19] and Table 2. For $\alpha=0$, Eqs. 22-25 give the volume fractions in case of a slurry of hemihydrate and water, while $\alpha=1$ describes the case of the fully hydrated (porous) gypsum, so including its voids.

The total void fraction $\left(\phi_{t}\right)$ is the sum of the volume fraction of water and volume fraction of shrinkage, so the total void fraction is equal to

$\phi_{\mathrm{t}}=\phi_{\mathrm{w}}+\phi_{\mathrm{s}}=\frac{\frac{w_{0}}{c_{0}}-\alpha \frac{v_{\mathrm{n}}}{v_{\mathrm{w}}} \frac{w_{\mathrm{n}}}{c}}{\frac{v_{\mathrm{c}}}{v_{\mathrm{w}}}+\frac{w_{0}}{c_{0}}}$

Table 2 Parameters of the paste model [19]

\begin{tabular}{llllll}
\hline Substance & $v_{\mathrm{c}} / v_{\mathrm{w}}$ & $w_{\mathrm{n}} / c$ & $v_{\mathrm{n}} / v_{\mathrm{w}}$ & $v_{\mathrm{n}} w_{\mathrm{n}} / v_{\mathrm{w}} c$ & $V_{\mathrm{s}} / v_{\mathrm{w}} c$ \\
\hline $\mathrm{C} \bar{S}(\gamma)$ & 0.39 & 0.265 & 0.60 & 0.16 & 0.106 \\
$\mathrm{C} \bar{S} \mathrm{H}_{0.5}(\alpha)$ & 0.36 & 0.186 & 0.81 & 0.15 & 0.035 \\
$\mathrm{C} \bar{S} \mathrm{H}_{0.5}(\beta)$ & 0.38 & 0.186 & 0.71 & 0.13 & 0.054 \\
\hline
\end{tabular}


The void fraction before mixing corresponds to the water volume fraction of the slurry $(\alpha=0)$ and reads

$\phi_{\mathrm{t}}=\frac{\frac{w_{0}}{c_{0}}}{\frac{v_{\mathrm{c}}}{v_{\mathrm{w}}}+\frac{w_{0}}{c_{0}}}$.

For a fully hydrated system $(\alpha=1)$, Eq. 26 yields

$\phi_{\mathrm{t}}=\frac{\frac{w_{0}}{c_{0}}-\frac{v_{\mathrm{n}}}{v_{\mathrm{w}}} \frac{w_{\mathrm{n}}}{c}}{\frac{v_{\mathrm{c}}}{v_{\mathrm{w}}}+\frac{w_{0}}{c_{0}}}$.

The void fraction of $\alpha$-hemihydrate based dihydrate after full hydration $(\alpha=1)$, following Table 2 , reads

$\phi_{\mathrm{t}}=\frac{\frac{w_{0}}{c_{0}}-0.15}{0.36+\frac{w_{0}}{c_{0}}}$.

This equation was also introduced already by Schiller [20], which was also used by other researchers [17, 21]. Brouwers [19] and Yu and Brouwers [22] have compared experimental values with the model presented here, in particular Eq. 28, for hardened $\beta$-hemihydrate $(\alpha=1)$ and found good agreement.

Equations 23, 24 and 27 are applicable to the hydration of $\alpha$ - and $\beta$-hemihydrate, for $0 \leq \alpha \leq 1$, so not only for fully hydrated binder only. In the next sections, they will be applied to a hydrating system, so $0<\alpha<1$, measured using the ultrasonic velocity.

\section{Hydration models}

'Sound velocity of materials' section addressed the sound velocity of the material in the initial and final state of hydration. But besides these both states, also the process in between is interesting. Therefore, first a model for the relation between sound velocity and hydration degree is given. For the study of the hydration, the relation to time is essential, therefore hydration degree is related to time by use of analytical hydration models in 'Relation between hydration degree and time' section.

\section{Relation between hydration degree and sound velocity}

Smith et al. [23] describe the relation between hydration mechanism and ultrasonic measurements in aluminous cement. They provide a correlation between hydration degree and ultrasonic measurements. This correlation reads

$\alpha=\frac{c_{\mathrm{e}}-c_{\mathrm{sl}}}{c_{\mathrm{hp}}-c_{\mathrm{sl}}}+\alpha_{0}$,

with $c_{\mathrm{e}}$ is the measured sound velocity through mix, $c_{\mathrm{s} l}$ is the sound velocity at moment the velocity starts increasing (so, of the slurry), $c_{\mathrm{hp}}$ is the sound velocity when the velocity stops increasing (so, of the hardened product) and $\alpha_{0}$ is the hydration degree at moment of $c_{\mathrm{sl}}$ (which is here zero). Equation 30 can be rewritten to

$c_{\mathrm{e}}=\alpha\left(c_{\mathrm{hp}}-c_{\mathrm{sl}}\right)+c_{\mathrm{sl}}$.

When it is invoked that at $\alpha=0$ corresponds to $c_{\mathrm{e}}=c_{\mathrm{s} 1}$ and at $\alpha=1$ corresponds to $c_{\mathrm{e}}=c_{\mathrm{hp}}$.

Relation between hydration degree and time

In literature, several different analytical hydration models are introduced. Most models are based on the work of either Schiller [6, 24-26] or of Ridge and Surkevicius [2729]. The equation of Schiller [6] has the advantage that it indirectly includes water/binder ratio in the parameters. The equation of Schiller [6] reads

$t=K_{1} \sqrt[3]{\alpha}+K_{2}(1-\sqrt[3]{1-\alpha})+K_{0}$

in which $K_{0}$ equals the induction time $\left(t_{0}\right)$. Schiller [6] emphasizes that $K_{1}$ and $K_{2}$ have clearly defined physical meanings and are not just fitting parameters.

Schiller [6] shows a number of simulations for the hydration of hemihydrate. In his simulations, $K_{1}$ is between 21 and $48.3 \mathrm{~min}$ and $K_{2}$ from 11 to $21.6 \mathrm{~min}$. Beretka and van der Touw [30] used value for $K_{1}$ between 37.8 and $43.5 \mathrm{~min}$ and between 15.1 and $30.3 \mathrm{~min}$ for $K_{2}$ for a mixture with wbr of 0.70. Fujii and Kondo [31] used $K_{1}=44 \mathrm{~min}$ and $K_{2}=$ $276 \mathrm{~min}$ for a wbr of 0.40 . Although none of these authors specify the type of hemihydrate used, from the hydration time one can assume that it concerned $\alpha$-hemihydrate. Singh and Middendorf [32] point out that the induction period for $\alpha$ hemihydrate hydration is shorter than that for $\beta$-hemihydrate. But they also point out that $\beta$-hemihydrate hydrates faster because of its higher surface area which provides more nucleation sites for the crystallization of gypsum.

\section{Experiments}

\section{Materials}

Within this research, $\beta$-hemihydrate is used as the binder. The hemihydrate used during the experiments was produced from flue gas desulphurization gypsum, which is commonly used for the production of gypsum plasterboards. The particle size distribution (PSD) is shown in Fig. 1. The used $\beta$ hemihydrate consists of $94.5 \%$ pure hemihydrate, $3.9 \%$ limestone and $1.6 \%$ other compounds [22]. The hemihydrate has a Blaine value of $3,025 \mathrm{~cm}^{2} / \mathrm{g}$ and a density of $2,619 \mathrm{~kg} / \mathrm{m}^{3}$. The Blaine value describes the fineness of the binder particle (hemihydrate). Hunger and Brouwers [33] point out that the Blaine test methods are not applicable for powders with higher fineness (i.e. particles $<10 \mu \mathrm{m}$ ). The 


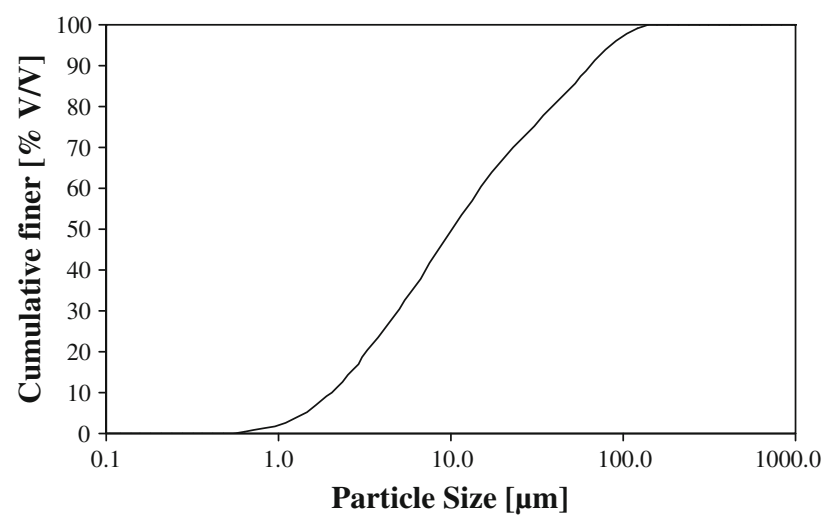

Fig. 1 Particle size distribution of applies hemihydrate

hemihydrates used has $50 \%$ of the particles smaller than $10 \mu \mathrm{m}$, therefore the Blaine value is less suitable. Another method to determine the fineness of powder is the use of specific surface area (SSA). Hunger [34] showed a method to calculate the specific surface area based on the PSD. Hunger and Brouwers [33] showed that there is a constant ratio between Blaine value and computed SSA. The Blaine value has to be multiplied by about 1.7 to obtain the SSA. Applied here, the SSA based on the given Blaine value would amount $5130 \mathrm{~cm}^{2} / \mathrm{g}$. The computation of the SSA using the PSD depends on the shape of the particles. For spheres, the shape factor equals unity. Using this shape factor, the SSA of the used hemihydrate would be $4432 \mathrm{~cm}^{2} / \mathrm{g}$. However, these powder particles are not spherical, and the amount of specific surface area is higher. To match computed SSA and Blaine value of $5130 \mathrm{~cm}^{2} / \mathrm{g}$, here a shape factor of 1.16 follows for the applied $\beta$-hemihydrate. It is noteworthy that Hunger and Brouwers [33] found shape-factor of 1.18 for $\alpha$-hemihydrate.

\section{Measurements}

The measurements were executed in cooperation with the Materialprüfungsanstalt of the University of Stuttgart

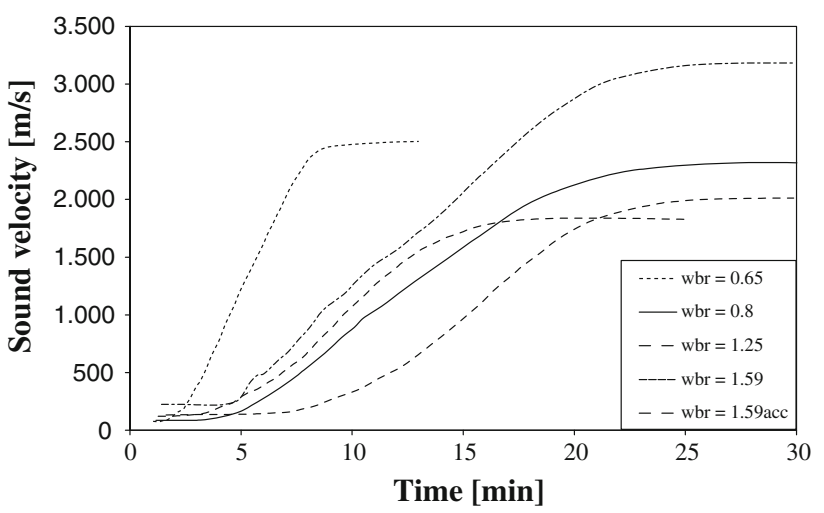

Fig. 2 Measured sound velocity by Grosse and Lehmann [35]

(Germany). The sound velocity of four water/binder ratios is measured during the experiments. The four water/binder ratios (wbr) are 0.63, 0.80, 1.25 and 1.59. Besides these four mixtures, also a mixture with wbr of 1.59 with $0.40 \%$ $(\mathrm{m} / \mathrm{m})$ accelerator is tested. Table 3 shows the mix-designs used during the experiments. Figure 2 shows the measured sound velocity during hydration of the four mixtures.

The hemihydrate hydration experiments with ultrasonic method were performed using the FreshCon system which was developed at the University of Stuttgart. The measurements are performed in a container, which consists of two polymethacrylate walls and u-shaped rubber foam element in the center, which are tied together by four screws with spacers. The volume of the mould is approximately $45 \mathrm{~cm}^{3}$ for the test. The measurements were performed with use of two Panametrics V106, $2.25 \mathrm{MHz}$ centre frequency sensors. For the processing of the measuring data during the experiments, in-house developed software (FRESHCON2) is used. More detailed information about the FreshCon system and the measurement procedure can be found in Reinhardt and Grosse [2].

The calculated void fractions of the mixtures in this research, based on the model of Brouwers [19], are given in Table 3 and shown in Fig. 3. Table 3 also shows the
Table 3 Mix designs, computed void fractions based on Brouwers [19] and the results of the ultrasonic measurements [35]

\begin{tabular}{llllll}
\hline & \multicolumn{2}{l}{ Mix design } & & \\
\cline { 2 - 6 } & $\mathrm{A}$ & $\mathrm{B}$ & $\mathrm{C}$ & $\mathrm{D}$ & $\mathrm{E}$ \\
\hline $\begin{array}{l}\text { Water/hemihydrate ratio } \\
\text { Accelerator (m/m on hemihydrates) }\end{array}$ & 0.63 & 0.8 & 1.25 & 1.59 & 1.59 \\
$\begin{array}{l}\text { Before hydration } \\
\quad \text { Computed void fraction }\end{array}$ & 0.624 & 0.678 & 0.767 & 0.807 & 0.807 \\
$\quad \begin{array}{l}\text { Measured sound velocity (m/s) } \\
\text { After hydration }\end{array}$ & 75 & 85 & 134 & 223 & 134 \\
$\quad \begin{array}{l}\text { Computed void fraction } \\
\text { Measured sound velocity (m/s) }\end{array}$ & 0.493 & 0.566 & 0.685 & 0.740 & 0.740 \\
\hline
\end{tabular}




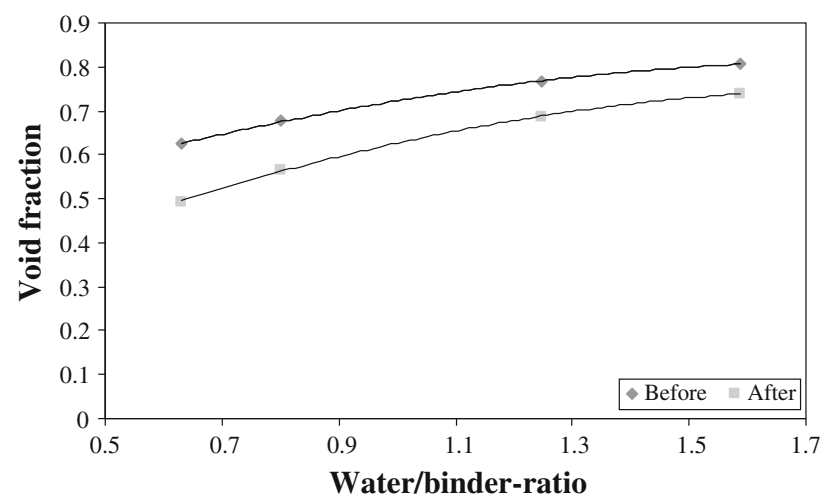

Fig. 3 Relation between water/binder ratio and computed void fraction based on Brouwers [19] before and after hydration
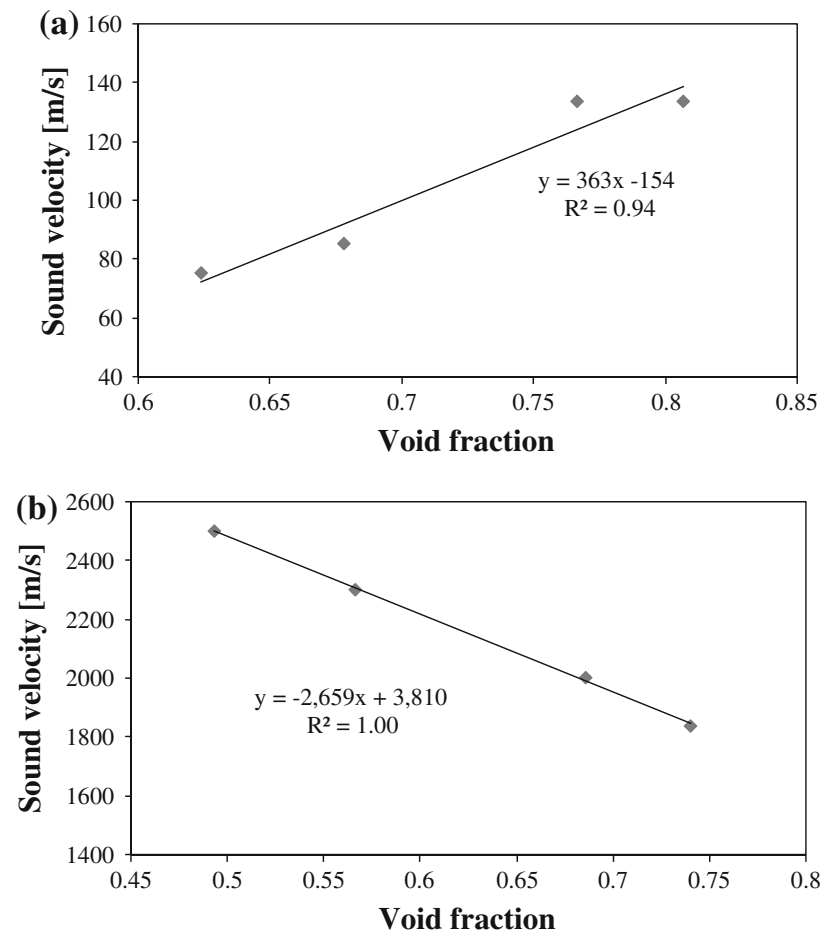

Fig. 4 Void fraction versus velocity a before hydration and $\mathbf{b}$ after hydration based on the experiments of Grosse and Lehmann [35]

measured ultrasonic velocity by Grosse and Lehmann [35]. Figure $4 \mathrm{a}$ and $\mathrm{b}$ is the graphic representations of the sound velocity data versus computed void fraction from Table 3. It can be noticed from the figures that there is a clear relation between void fraction and velocity as well before as after hydration, so $\alpha=0$ and $\alpha=1$, respectively. But the trend is exactly opposite before and after hydration. Before hydration, the velocity increases with increasing void fraction (i.e. water content), while the velocity is decreasing with increasing void fraction after hydration. In the next section, relations will be established between the volumetric composition (at $\alpha=0$ and $\alpha=1$ ) and sound velocity.

\section{Applying the volumetric models to sound velocity measurements}

Sound velocity through a slurry

Table 4 shows the results of Eq. 3 with $K_{\mathrm{s}}=52.4 \mathrm{GPa}$, $K_{\mathrm{f}}=2.2 \mathrm{GPa}$ (Table 1 ). The calculated sound velocities with Eq. 3 are much higher than the measured sound velocity during the experiments. The main reason for this is the overestimation of the fluid bulk modulus as described by Robeyst et al. [1]. Therefore, the bulk modulus of the fluid is corrected with Eq. 5, with the bulk modulus of air $142 \mathrm{kPa}$ and the bulk modulus of water $2.2 \mathrm{GPa}$ (Table 1). Based on this equation, the air content $\left(C_{\text {air }}\right)$ of the pore fluid can be derived, which is included in Table 4 .

Further computations reveal that the volume fraction of air divided by the volume fraction of the binder in the slurry lies in a very small range (Table 4). This could indicate that air entered the slurry on the surface of the hemihydrate particles and a typical value is thus $2.7 \%$ $(\mathrm{V} / \mathrm{V})$ or $10 \mathrm{~mL}$ air per kg hemihydrate. Given the Blaine value of $3025 \mathrm{~cm}^{2} / \mathrm{g}$, this would mean $3.28 \times 10^{-6} \mathrm{~mL}$ air per $\mathrm{cm}^{2}$ hemihydrate surface $\left(=3.28 \times 10^{-2} \mathrm{~mL} / \mathrm{m}^{2}\right)$, corresponding to an air layer thickness of $32.8 \mathrm{~nm}$.

Sound velocity of solid: indirect method

Table 5 shows the results of Eqs. $11-13$ with $K_{\mathrm{s}}=44$ $\mathrm{GPa}, K_{\mathrm{f}}=2.2 \mathrm{GPa}$ and $v=0.33$ (Table 1). The use of bulk-modulus based on Eqs. 11 and 13 lead to an underestimation, while Eq. 12 leads to an overestimation of the velocity. Table 5 also shows the results for Eqs. 14-16. The best estimation of the sound velocity was found using Eq. 16. The difference between predicted values for this combination and experimental value becomes slightly larger when the water/binder ratio increases.

Table 4 Results of the slurry method Eq. 3 without entrapped air and derived air content with the use of the slurry method (Eqs. 3-5)

\begin{tabular}{lllllll}
\hline Wbr & $\begin{array}{l}\text { Initial } \\
\text { void } \\
\text { fraction }\end{array}$ & $\begin{array}{l}\text { Measured } \\
\text { velocity } \\
(\mathrm{m} / \mathrm{s})\end{array}$ & $\begin{array}{l}\text { Computed } \\
\text { velocity } \\
(\text { Eq. 3) }\end{array}$ & \begin{tabular}{l} 
Derived air content \\
\cline { 5 - 6 }
\end{tabular} & $\begin{array}{l}C_{\text {air }} \\
(\%)\end{array}$ & $\begin{array}{l}V_{\text {air }} / V_{\mathrm{HH}} \\
(\%)\end{array}$ \\
\hline $\mathrm{A}$ & 0.63 & 0.624 & 75 & 1520 & 1.69 & 2.85 \\
$\mathrm{~B}$ & 0.8 & 0.678 & 85 & 1511 & 1.41 & 3.00 \\
$\mathrm{C}$ & 1.25 & 0.767 & 134 & 1503 & 0.63 & 2.09 \\
$\mathrm{D}$ & 1.59 & 0.807 & 223 & 1500 & 0.23 & 0.98 \\
$\mathrm{E}$ & $1.59^{\text {acc }}$ & 0.807 & 134 & 1500 & 0.66 & 2.78 \\
\hline
\end{tabular}

acc stands for $0.40 \% \mathrm{~m} / \mathrm{m}$ accelerator added 
Table 5 Results of the indirect method (Eqs. 11-16) and the direct method (Eqs. 17-21) with sound velocity $(\mathrm{m} / \mathrm{s})$, specific density $\left(\mathrm{kg} / \mathrm{m}^{3}\right)$, bulk moduli $(\mathrm{GPa})$, shear moduli $(\mathrm{GPa})$, and poisson ratio (-) of gypsum taken from Table 1

\begin{tabular}{|c|c|c|c|c|c|c|}
\hline & $c_{\mathrm{s}}(\mathrm{m} / \mathrm{s})$ & A & B & $\mathrm{C}$ & $\mathrm{D}$ & $\mathrm{E}$ \\
\hline Water/binder ratio & & 0.63 & 0.8 & 1.25 & 1.59 & 1.59 \\
\hline Accelerator & & & & & & $0.40 \%$ \\
\hline Final void fraction & & 0.493 & 0.566 & 0.685 & 0.74 & 0.74 \\
\hline Measured & & 2500 & 2300 & 2000 & 3172 & 1835 \\
\hline \multicolumn{7}{|l|}{ Indirect method } \\
\hline Eq. 11 & & 1597 & 1545 & 1491 & 1476 & 1476 \\
\hline Eq. 12 & & 3749 & 3601 & 3298 & 3122 & 3122 \\
\hline Eq. 13 & & 2130 & 2029 & 1822 & 1699 & 1699 \\
\hline Eq. 14 & & 1963 & 1899 & 1833 & 1815 & 1815 \\
\hline Eq. 15 & & 4609 & 4427 & 4055 & 3838 & 3838 \\
\hline Eq. 16 & & 2618 & 2495 & 2240 & 2089 & 2089 \\
\hline \multicolumn{7}{|l|}{ Direct method } \\
\hline Eq. 17 & 6800 & 3448 & 2951 & 2142 & 1768 & 1768 \\
\hline Eq. 18 & 6800 & 3843 & 3373 & 2577 & 2193 & 2193 \\
\hline Eq. 18 & 4571 & 2584 & 2267 & 1732 & 1474 & 1474 \\
\hline Eq. 19 & 6800 & 4186 & 3799 & 3167 & 2876 & 2876 \\
\hline Eq. 20 & 6800 & 4670 & 4301 & 3666 & 3356 & 3356 \\
\hline Eq. 20 & 4571 & 3410 & 3195 & 2822 & 2637 & 2637 \\
\hline Eq. 21 & 6800 & 2476 & 2263 & 1985 & 1878 & 1878 \\
\hline Eq. 21 & 5440 & 2367 & 2184 & 1939 & 1845 & 1845 \\
\hline Eq. 21 & 4571 & 2271 & 2114 & 1899 & 1814 & 1814 \\
\hline
\end{tabular}

Sound velocity of solid: direct method

The results of Eqs. 17-21 are shown in Table 5. It can be noticed that the predicted values based on Eq. 17 differ from the measured values. Equation 18 results in a too high velocity for all measurements when using the sound speed of $6800 \mathrm{~m} / \mathrm{s}$ for gypsum (Table 1). When using $4571 \mathrm{~m} / \mathrm{s}$ as sound velocity of gypsum as given by Dalui et al. [17], the measurements for the first two experiments show good agreement. But the values for the mixtures with higher water/binder ratio (e.g. higher void fraction) are too low. Both Eqs. 19 and 20 lead to an overestimation compared with the experimental value.

The predicted values based on Eq. 21 are close to the experimental values for all water/binder ratios. For the lowest water/binder ratios, the predictions are too low, while for the higher water/binder ratios the prediction tends to overestimate the velocity. The best results for Eq. 21 are found with the solid sound velocity of $6800 \mathrm{~m} / \mathrm{s}$.

\section{Conclusions}

The model given by Robeyst et al. [1] for predicting the sound velocity of an air-water-solids slurry is compatible with the experiments assuming a constant air content of $2.7 \%(\mathrm{~V} / \mathrm{V})$ based on the volume of hemihydrate. In case of the hardened (porous) material, the closest fit between experimental and predicted value is found by the use of the direct method. The best results were obtained with the series arrangement based on the empirical sound velocity values; Eq. 21 with $c_{\mathrm{s}}=6800 \mathrm{~m} / \mathrm{s}$ and $c_{\mathrm{f}}=1497$. Also the equation of Dalui et al. [17] (Eq. 18) shows a good agreement for the two lowest void fractions, using with $c_{\mathrm{s}}=4571 \mathrm{~m} / \mathrm{s}$ and $n=0.84$.

\section{Analysis of measurements using the hydration model}

In the previous section, the ultrasonic measurements were compared with the prediction based on theoretical equations for initial and final state of the hydration. The next step is to apply the described models from 'Hydration models' section on the measured hydration curves from 'Experiments' section.

\section{Analysis}

The sound velocity graphs contain a series of characteristic important points. For instance, $t_{\alpha=0}$ is the point in time at which the sound velocity starts to increase. The time until this point is called the induction time. The previous section showed that the sound velocity of this point can be best described based with model of Robeyst (Eqs. 3-5). And $t_{\alpha=1}$ is the moment in time at which hydration is completed. The previous section showed that this could be best described by equation given by Ye (Eq. 21). These points 
can be directly related to the parameters of the Schiller model. $K_{0}$ is equal to $t_{\alpha=0}$ and $K_{0}+K_{1}+K_{2}$ equals to $t_{\alpha=1}$, see Eq. 32. Figure 5 shows both points in time for wbr $=0.80$.

The exact determination of the value of $t_{\alpha=1}$ is challenging, since it requires that the moment of full hydration is clearly visible in the sound velocity graphs. Since this is not really the case, another method is applied here. In this method, the time $\left(t_{\alpha=0.5}\right)$ needed to perform half of the hydration $(\alpha=0.5)$ is determined. Based on Eq. 31, the sound velocity describing half hydration equals the average of the sound velocity of slurry and of hardened product. Table 6 and Fig. 6 a show the determined values for $t_{\alpha=0.5}$, based on the sound velocity curves.

In order to determine the individual values of $K_{0}, K_{1}$ and $K_{2}$, the model is fitted to the experimental sound velocity curves taking into account the already determined values for $t_{\alpha=0.5}$. The fitting is performed using $t_{\alpha=0.5}$ of the Schiller model (Eq. 32):

$$
\begin{aligned}
t_{\alpha=0.5} & =K_{1} \sqrt[3]{0.5}+K_{2}(1-\sqrt[3]{1-0.5})+K_{0} \\
& =\left(K_{1}-K_{2}\right) \sqrt[3]{0.5}+K_{2}+K_{0}
\end{aligned}
$$

Table 6 and Fig. $6 \mathrm{~b}$ show the results of the fitting. From Fig. 6a, one can notice that the total time of hydration $\left(t_{\alpha=1.0}\right)$ increased with an increasing volume fraction of water in the mix. Both $K_{1}$ and $K_{2}$ seem linearly related to

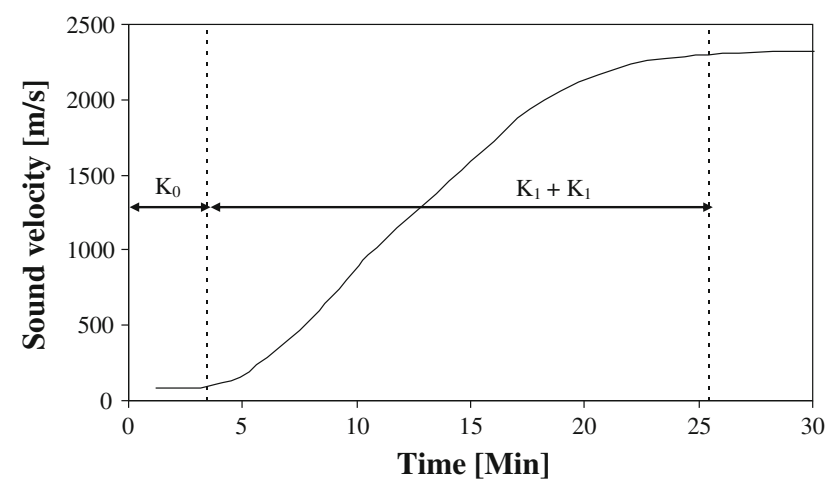

Fig. 5 Determination of $K_{0}$ and $K_{1}+K_{2}$ for experimental results with wbr $=0.80$ the volume fraction water, but these fits are not really conclusive. Ignoring the results of $w b r=1.59$, there is a more clear trend visible. When doing this, $K_{0}$ and $K_{1}$ are related to the volume fraction water, while $K_{2}$ is unrelated to this property. The omission of outlier wbr $=1.59$ makes sense because the sound speed of the mixture is not in line with the rest of the measurements, as well as the position of the sound velocity curve.

The current research reveals the presence and magnitude of induction times $\left(K_{0}\right.$ or $\left.t_{\alpha=0}\right)$, while Schiller [6] neglects the induction time when applying his model. When comparing the derived value of $K_{1}$ and $K_{2}$ with the values given by Schiller [6] and Beretka and van der Touw [30], one can notice that here the values for $K_{1}$ and $K_{2}$ are lower. The lower values compared to literature [6, 30, 31] can be explained by the fact that these values were most probably
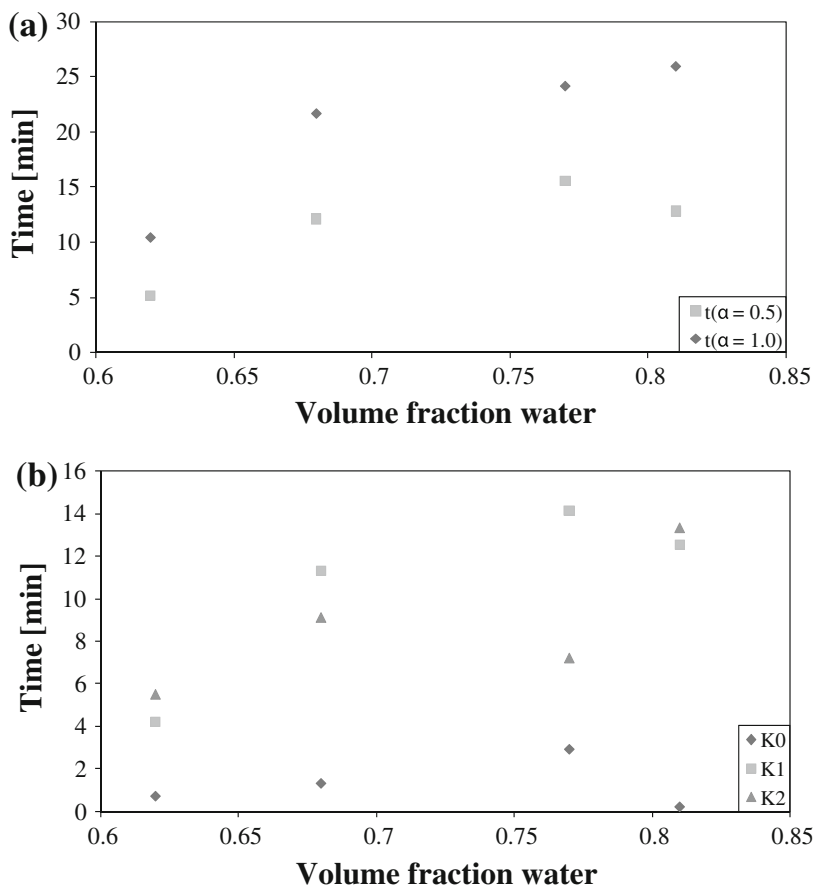

Fig. 6 a Determined values of $t_{\alpha=0.5}$ and $t_{\alpha=1}\left(K_{0}+K_{1}+K_{2}\right)$ versus the initial volume fraction of water. b Derived values of $K_{0}\left(t_{\alpha=0}\right), K_{1}$ and $K_{2}$ by fitting of the experimental and simulated sound velocity curves without accelerator
Table 6 Determined value for $t_{\alpha=0.5}$ and derived values for $K_{1}$ and $K_{2}$ by fitting

acc stands for $0.40 \% \mathrm{~m} / \mathrm{m}$ accelerator added

\begin{tabular}{lllllllll}
\hline Mix & wbr & $\begin{array}{l}\text { Initial calculated } \\
\text { water fraction } \phi_{\mathrm{w}}\end{array}$ & $\begin{array}{l}\text { Initial calculated } \\
\text { solid fraction } \phi_{\mathrm{HH}}\end{array}$ & $t_{\alpha=0.5}$ & $K_{0}$ & $K_{1}$ & $K_{2}$ & $t_{\alpha=1}$ \\
\hline A & 0.65 & 0.62 & 0.38 & 5.16 & 0.7 & 4.2 & 5.5 & 10.4 \\
B & 0.8 & 0.68 & 0.32 & 12.14 & 1.3 & 11.3 & 9.1 & 21.7 \\
C & 1.25 & 0.77 & 0.23 & 15.60 & 2.9 & 14.1 & 7.2 & 24.2 \\
D & 1.59 & 0.81 & 0.19 & 12.86 & 0.2 & 12.5 & 13.3 & 26.0 \\
E & $1.59^{\text {acc }}$ & 0.81 & 0.19 & 9.52 & 2.2 & 6.1 & 12.0 & 20.3 \\
\hline
\end{tabular}


determined for $\alpha$-hemihydrate. Since $\beta$-hemihydrate hydrates faster because of its larger surface area, it provides more nucleation sites for the crystallization of dihydrate [32]. The nucleation of gypsum is, according to the model of Schiller, governed by $K_{1}$.

Literature does not provide additional information describing the effect of water/binder ratio on $K_{1}$ and $K_{2}$, neither for $\alpha$ - nor $\beta$-hemihydrate. A research on the hydration of calcium aluminate cement using the Schiller model by Smith et al. [23] showed a relation between $K_{1}$ and water binder ratio, while the value of $K_{2}$ was constant within small water/binder ratio range. The current research shows partly the same positive relation between $K_{1}$ and water/binder ratio, particularly if the measurement with water/binder ratio of 1.59 is omitted. Furthermore, also here a relatively constant value of $K_{2}$ is observed.

\section{Conclusions}

It is shown that the relation between hydration degree and sound velocity as given by Smith et al. [23] is applicable for the hydration of hemihydrate. Within this model, the equations of Robeyst et al. [1] and Ye [18] can be used to describe the sound velocity at the start and end, respectively, of the hydration process.

Furthermore, the hydration model of Schiller is applied on the ultrasonic sound velocity measurements. A fitting of the Schiller [6] model to the experimental results has been performed using the $t_{\alpha=0.5}$ method. The analysis of the results showed that $K_{0}$ and $K_{1}$ are linearly dependent on the water/ binder ratio, while $K_{2}$ is unrelated to the water/binder ratio. $K_{0}, K_{1}$ and $K_{2}$ describe the induction time, the dihydrate growth and the hemihydrates dissolution, respectively. Furthermore, it is noticed that the induction time $\left(t_{\alpha=0}\right.$ or $\left.K_{0}\right)$ is linearly related to the volume fraction water and, therefore, directly related to the water/binder ratio.

\section{Alternative method}

In the previous sections, the sound speed through porous media was predicted based on the calculated void fraction.
In this section, the void fraction and density are calculated based on the measured sound velocity through a porous hardened material. Equations 18 and 21 can be rewritten as

$\phi_{\mathrm{t}}=1-\left(\frac{c_{\mathrm{e}}}{c_{\mathrm{s}}}\right)^{\frac{1}{n}}=1-\left(\frac{c_{\mathrm{e}}}{c_{\mathrm{s}}}\right)^{\frac{1}{0.84}}$

or

$\phi_{\mathrm{t}}=\left(\frac{c_{\mathrm{f}} c_{\mathrm{s}}}{c_{\mathrm{e}}}-c_{\mathrm{f}}\right) \cdot \frac{1}{c_{\mathrm{s}}-c_{\mathrm{f}}}$,

respectively, with $c_{\mathrm{e}}$ is the measured sound velocity during experiments (Table 3 ), $c_{\mathrm{s}}$ the sound velocity through nonporous material and $c_{\mathrm{f}}$ the sound velocity through the fluid in the pores (Table 1). Table 7 shows the derived void fractions for gypsum based on Eqs. 34 and 35 using the experimental values from 'Experiments' section.

The results of Eq. 34 show that better results are obtained with a sound velocity of $4571 \mathrm{~m} / \mathrm{s}$ compared to solid sound velocity of $6800 \mathrm{~m} / \mathrm{s}$. This finding is in line with 'Experiments' section, which also showed better results with a solid sound velocity of $4571 \mathrm{~m} / \mathrm{s}$. The results show a very close fit between the derived void fraction from Eq. 35 and the void fractions from model of Brouwers [19], governed by the water/binder ratio. The difference between model and derived value is limited except for $w b r=1.59$ without accelerator.

The derived void fraction could be useful for deriving the density of gypsum-based materials, since the commonly used method for the determination of density of building materials is not suitable. This method included the measuring of the mass when the sample is submersed in water. Since gypsum is soluble in water, this could lead to changes in the material. The equation for the density of gypsum based on the (derived) void fraction reads

$\rho_{\mathrm{e}}=\phi_{\mathrm{t}} \rho_{\mathrm{f}}+\left(1-\phi_{\mathrm{t}}\right) \rho_{\mathrm{s}}$

with $\rho_{\mathrm{e}}$ as the apparent density, $\phi_{\mathrm{t}}$ the void fraction, $\rho_{\mathrm{f}}$ and $\rho_{\mathrm{s}}$ the specific density of the fluid and the solid, respectively. When combining Eq. 36 with Eqs. 34 and 35 , one can obtain the following equations for the effective density of the gypsum (e.g. applied in plasterboard) based on the measured effective sound velocity
Table 7 Derived void fractions based on measured sound velocity and Eqs. 34, 35

\begin{tabular}{lllll}
\hline Mix & $\begin{array}{l}\text { Calculated final void } \\
\text { fraction [19] }\end{array}$ & $\begin{array}{l}\text { Prediction void } \\
\text { fraction Eq. 34 } \\
c_{\mathrm{s}}=6800 \mathrm{~m} / \mathrm{s}\end{array}$ & $\begin{array}{l}\text { Prediction void } \\
\text { fraction Eq. 34 } \\
c_{\mathrm{s}}=4571 \mathrm{~m} / \mathrm{s}\end{array}$ & $\begin{array}{l}\text { Prediction void } \\
\text { fraction Eq. 35 }\end{array}$ \\
\hline $\mathrm{A}$ & 0.493 & 0.696 & 0.512 & 0.485 \\
$\mathrm{~B}$ & 0.566 & 0.724 & 0.558 & 0.552 \\
$\mathrm{C}$ & 0.685 & 0.767 & 0.626 & 0.677 \\
$\mathrm{D}$ & 0.740 & 0.596 & 0.352 & 0.323 \\
$\mathrm{E}$ & 0.740 & 0.789 & 0.662 & 0.764 \\
\hline
\end{tabular}


$\rho_{\mathrm{e}}=\rho_{\mathrm{f}}+\left(\rho_{\mathrm{s}}-\rho_{\mathrm{f}}\right) \cdot\left(\frac{c_{\mathrm{e}}}{c_{\mathrm{s}}}\right)^{\frac{1}{0.84}}$

and

$\rho_{\mathrm{e}}=\rho_{\mathrm{s}}-\frac{\rho_{\mathrm{s}}-\rho_{\mathrm{f}}}{c_{\mathrm{s}}-c_{\mathrm{f}}} \cdot\left(\frac{c_{\mathrm{f}} c_{\mathrm{s}}}{c_{\mathrm{e}}}-c_{\mathrm{f}}\right)$,

respectively. Summarizing, based on the measured sound velocity both void fraction and apparent density can be predicted.

\section{Conclusions}

In the current article, three situations were distinguished; slurry (starting situation), hardened product (end situation) and material during hydration (situation in between slurry and hardened product). The following main findings with regard to these situations were found:

- The model of Robeyst et al. [1] for the sound velocity of a slurry showed a good agreement with the experimental values, when taking into account an air content of $2.7 \%(\mathrm{~V} / \mathrm{V})$ on applied hemi-hydrate.

- A very good agreement for porous hardened materials was found between the experimental and theoretical values with the series arrangement according to Ye [18] (Eq. 21) with $c_{\mathrm{s}}=6800 \mathrm{~m} / \mathrm{s}$ for dihydrate.

- The ultrasonic sound velocity through the hydrating material, which is related to the hydration curve, can be described using the combination of the hydration model of Schiller [6] and the relation between hydration degree and sound velocity given by Smith et al. [23].

Furthermore, the analysis of the results of the fitting with the Schiller model showed that the parameters $K_{0}$ (induction time) and $K_{1}$ (gypsum growth) are positively linearly related to the water/binder ratio. The parameter $K_{2}$ (dissolution of hemihydrate) is unrelated to the volume fraction water.

\begin{abstract}
Acknowledgements The authors wish to express their sincere thanks to Prof. Dr.-Ing. habil. C.S. Grosse and Dipl.-Ing. F. Lehmann of Non-destructive Testing Lab, Technical University of Munich, Germany, for performing the ultrasonic tests, the European Commission (I-SSB Project, Proposal No. 026661-2) and the following sponsors of the research group: Bouwdienst Rijkswaterstaat, GranietImport Benelux, Kijlstra Betonmortel, Struyk Verwo, Insulinde, Enci, Provincie Overijssel, Rijkswaterstaat Directie Zeeland, A\&G Maasvlakte, BTE, Alvon Bouwsystemen, V.d. Bosch Beton, Selor, Twee "R" Recyling, GMB, Schenk Concrete Consultancy, De Mobiele Fabriek, Creative Match, Intron, Geochem Research and Icopal (chronological order of joining).
\end{abstract}

Open Access This article is distributed under the terms of the Creative Commons Attribution Noncommercial License which permits any noncommercial use, distribution, and reproduction in any medium, provided the original author(s) and source are credited.

\section{References}

1. Robeyst N, Gruyaert E, Grosse CU, De Belie ND (2008) Cem Concr Res 38(10):1169

2. Reinhardt HW, Grosse CU (2004) Constr Build Mater 18(3):145

3. De Belie ND, Grosse CU, Kurz J, Reinhardt HW (2005) Cem Concr Res 35(11):2087

4. Ylmén R, Jäglid U, Steenari B-M, Panas I (2009) Cem Concr Res 39(5):433

5. Reinhardt HW, Grosse CU, Herb A, Weiler B, Schmidt G. Verfahren zur Untersuchung eines erstarrenden und/oder erhärtenden Werkstoffs mittels Ultraschall, U.S. Patent 19856259.41999

6. Schiller K (1974) J Appl Chem Biotechnol 24(7):379

7. Sayers CM, Dahlin A (1993) Adv Cem Based Mater 1(1):12

8. Robeyst N, Grosse CU, De Belie N (2009) Cem Concr Res 39(10):868

9. Losso M, Viveiros E (2005) Sound insulation of gypsum board in practice. Presented at the 2005 Congress and Exposition on Noise Control Engineering, Rio de Janeiro, Brazil, 2005

10. Harker AH, Temple JAG (1988) J Phys D 21(11):1576

11. Austin JC, Holmes AK, Tebbutt JS, Challis RE (1996) Ultrasonics 34(2-5):369

12. Gómez Álvarez-Arenas TE, Elvira Segura L, Riera Franco de Sarabia E (2002) Ultrasonics 39(10):715

13. Hoyos M, Bacri JC, Martin J, Salin D (1994) Phys Fluids 6(12):3809

14. Landau L (1986) Theory of elasticity, 3rd edn. Pergamon Press, Oxford

15. Arnold M, Boccaccini AR, Ondracek G (1996) J Mater Sci 31(6): 1643. doi:10.1007/BF00357876

16. Roth DJ, Stang DB, Swickard SM, DeGuire MR (1990) Review and statistical analysis of the ultrasonic velocity method for estimating the porosity fraction in polycrystalline materials. NASA, Cleveland, $\mathrm{OH}$

17. Dalui SK, Roychowdhury M, Phani KK (1996) J Mater Sci 31(5):1261. doi:10.1007/BF00353105

18. Ye G (2003) Experimental study and numerical simulation of the development of the microstructure and permeability of cementious materials. PhD-Thesis, Delft University of Technology, The Netherlands

19. Brouwers HJH (2011) A hydration model of Portland cement using the work of Powers and Brownyard. Portland Cement Association, Skokie, IL

20. Schiller KK (1958) In: Walton WH (ed) Mechanical properties of non-brittle materials. Butterworths Sci Pub, London, pp 35-49

21. Phani KK, Niyogi SK, Maitra AK, Roychaudhury M (1986) J Mater Sci 21(12):4335. doi:10.1007/BF01106552

22. Yu QL, Brouwers HJH (2011) Constr Build Mater 25(7):3149

23. Smith A, Chotard T, Gimet-Breart N, Fargeot D (2002) J Eur Ceram Soc 22(12): 1947

24. Schiller K (1962) J Appl Chem 12(3):135

25. Schiller K (1963) J Appl Chem 13(12):572

26. Schiller K (1965) Nature 205:1208

27. Ridge MJ, Surkevicius H (1961) J Appl Chem 11(11):420

28. Ridge MJ, Surkevicius H (1962) J Appl Chem 12(6):246

29. Ridge MJ, Surkevicius H (1966) J Appl Chem 16(3):78

30. Beretka J, van der Touw JW (1989) J Chem Technol Biotechnol 44(1): 19

31. Fujii K, Kondo W (1986) J Chem Soc Dalton Trans 4:729

32. Singh NB, Middendorf B (2007) Prog Cryst Growth Charact Mater 53(1):57

33. Hunger M, Brouwers HJH (2009) Cem Concr Compos 31(1):39

34. Hunger M (2010) An integral design concept for ecological selfcompacting concrete. PhD Thesis, Eindhoven University of Technology, Eindhoven, The Netherlands 
35. Grosse U, Lehmann F (2008) Ultrasound measurements of the hydration rate of hemihydrates. Materialprufungsanstalt, Universitat Stuttgart, Stuttgart, Germany

36. Lide DR (2003) CRC handbook of chemistry and physics, 84th edn. CRC Press, Boca Raton, FL
37. Schofield PF, Stretton IC, Knight KS, Hull S (1997) Physica B 234-236:942

38. Meille S, Garboczi EJ (2001) Model Simul Mater Sci Eng 9(5):371

39. Haecker CJ et al (2005) Cem Concr Res 35(10):1948 